\title{
infâncias e formação docente: gestos, sentidos e começos
}

\author{
camila machado de lima ${ }^{1}$ \\ universidade federal do estado do rio de janeiro, brasil
}

resumo

O presente texto é um ensaio sobre infância e formação docente, tecendo aproximações e encontros que coloquem em questão a escola, a educação, a docência, o tempo. A infância não é considerada categoria de tempo cronológico, mas uma força instauradora de possíveis, impossíveis, perguntas, interrupções. A infância é afirmada para além de uma fase etária, compreendida como existência, vida, encarnada em qualquer corpo e em outra temporalidade. Interessa perguntar pelas infâncias que atravessam a formação docente e, quiçá, pensar não apenas como formamos a infância, mas como as infâncias nos formam. O que elas provocam no fazer docente? Em que condições estas infâncias surgem? Seria o formar-se docente um amadurecimento da infância, na infância ou pela infância? Que gestos rasgam e explodem com os modos que nos habituamos a estar com as crianças e com os modos que estamos habituamos a nos formar docentes? Essas perguntas vêm me acompanhando no desafio de dedicar sensibilidade, atenção e escuta aos sentidos que emanam da infância, e a infância que emana dos sentidos, no exercício de ser professora de Educação Infantil. Portanto, este trabalho se inspira em infâncias de crianças da Educação Infantil do Colégio Pedro II, em infâncias da minha docência com estes sujeitos, em inícios, aberturas e começos que potencializam habitar a escola e fazer-se docente de um jeito infantil.

palavras-chave: infância; formação docente; educação

infancias y formación docente: gestos, sentidos y comienzos

\section{resumen}

El presente texto es un ensayo sobre infancia y formación docente, entrelazando aproximaciones y encuentros que coloquen en interrogación la escuela, la educación, la docencia y el tiempo. La infancia no es considerada categoría de tiempo cronológica y si una fuerza instauradora de posibles, imposibles, preguntas, interrupciones. La infancia es afirmada más allá de una fase etaria, comprendida como existencia, vida, encarnada en cualquier cuerpo y en otra temporalidad. Nos interesa preguntarnos, por las infancias que atraviesan la formación docente y, quizás, pensar no solo como formamos la infancia, sino como las infancias nos forma. ¿Qué crean ellas -las infancias- en las prácticas docente? ¿En qué condiciones estas infancias surgen? ¿Sería el formarse docente un amadurecimento de la infancia, en la infancia o por la infancia? ¿Que gestos rasgan y explotan los modos con los que habitualmente estamos con los niños y niñas y con los modos que habitualmente nos forman docente? Esas preguntas me vienen acompañando en el desafío de dedicar sensibilidad, atención y escucha a los sentidos que emanan de la infancia, y la infancia que emana de los sentidos, en el ejercicio de ser profesora de Educacion Infantil. Por tanto, este trabajo se inspira en infancias de niños y niñas de la Educación Infantil del Colegio Pedro II, en infancias de mi docencia con estas personas, en inicios, aberturas y comienzos que potencializan habitar la escuela y hacerse docente de un modo infantil.

palabras clave: infancia; formación docente; educación.

\footnotetext{
${ }^{1}$ E-mail: camila.cmlima@hotmail.com
} 


\section{childhood and teacher education: gestures, senses and beginnings}

abstract

The present text is an essay on childhood and teacher education, making approximations and meetings that put in question the school, the education, the teaching, the time. Childhood is not considered a category of chronological time, but an establishing force of possibility, impossibility, questions, interruptions. Childhood is affirmed beyond an age, understood as existence, life, embodied in any body and in another temporality. It is interesting to ask about the childhoods that go through the teacher formation and, perhaps, think not only how we form childhood, but how childhood forms us. How do they potencialize teachers work? Under what conditions do these childhoods arise? Is the teacher becoming a maturation of childhood, childhood or childhood? What gestures tear and explode with the ways we get used to being with the children and the ways we are used to becoming teachers? These questions have accompanied me in the challenge of devoting sensitivity, attention and listening to the senses emanating from childhood, and the childhood that emanates from the senses, in the exercise of being a teacher of Early Childhood Education. Therefore, this work is inspired by the childhoods of children of the Secondary Education of Pedro II College, in childhoods of my teaching with these subjects, in beginnings, openings and beginnings that potentiate to inhabit the school and become a teacher in a childish way.

keywords: childhood; teacher training; education 
infâncias e formação docente: gestos, sentidos e começos

introdução: infâncias desta escrita...

A verdade da infância não está no que dizemos dela, mas no que ela nos diz no próprio acontecimento de sua aparição entre nós, como algo novo

(Jorge Larrosa, 2013).

Falar de infância, escrever sobre infância, pesquisar infância, sentir infância... Escolhi a infância - ou fui escolhida por ela? - como potência para este texto. Mas, de que infância estou falando e sendo atravessada? Alguns autores vêm me ajudando a compreender infância a partir de outros lugares, a percebê-la fora de um tempo cronológico e marcado para tal, a colocar-nos disponível e atenta para encontrá-la (ou sermos encontrada por ela?).

Giorgio Agamben, Jorge Larrosa, Carlos Skliar, Walter Kohan e Bernardina Leal vêm me acompanhando não só no modo conceitual de compreender infância, contudo na possibilidade de existência, vida, encarnada em qualquer corpo e em outra temporalidade. Interessa-me perguntar pelas infâncias que atravessam a formação docente e, quiçá, pensar não apenas como formamos a infância, mas como as infâncias nos formam. O que elas provocam no fazer docente? Em que condições estas infâncias surgem? Seria o formar-se docente um amadurecimento da infância, na infância ou pela infância? Que gestos rasgam e explodem com os modos que nos habituamos a estar com as crianças e com os modos que estamos habituados a nos formar docentes?

Tais questões começam a surgir desde o meu encontro com as crianças, enquanto professora de Educação Infantil. Esses encontros, além de perguntas, sentidos e silêncios que vão me habitando, me provocam a pensar uma formação docente outra, uma formação atravessada não somente por saberes e conhecimentos, mas também, por gestos, olhares, palavras, infâncias... 
Em uma conversa com Carlos Skliar, no “Seminário Experiência, Alteridade e Educação: relacionar-se na diferença", promovido em 2016 pelo GPPF², ele nos lançou um convite: “Como podemos criar infância para frente?" Pergunta-convite que vem me provocando para pensar formação docente na educação infantil ou formação infantil na docência. Esta escrita, parte de minha pesquisa de Doutorado, se dedica, então, a tecer aproximações e possibilidades que potencializem pensar e viver aberturas e começos para habitar a escola e fazer-se docente de um jeito infantil.

Este artigo compartilha um processo de pesquisa da própria prática, apoiando-se no que algumas autoras dos Estudos do Cotidiano chamam de "professora-pesquisadora" (GARCIA; ALVES, 2002), na aposta de que docentes podem realizar pesquisa sem, necessariamente, estarem vinculados à academia. Sendo assim, assumo essa perspectiva, uma vez que tais reflexões e processos vividos com as crianças que trago aqui para conversar acontecem não somente com o ingresso no doutorado, mas também no processo de formação experienciado, em especial na docência. Por isso, o uso, em alguns momentos, da primeira pessoa do singular, pois estou imersa e inscrita nesta escrita e pesquisa que compartilho.

No processo de viver uma pesquisa da própria prática, a escrita deste artigo também anuncia perguntas que não me detenho a responder neste texto, mas a pensar com elas e com os autores que convido para dialogar acerca da potência das nossas infâncias. Desse modo, as perguntas demarcam um horizonte a inspirar a continuidade de seguir pensando-as na pesquisa do doutorado e na vida... Nesse sentido, inicio apresentando algumas considerações teóricas a respeito do conceito de infância e tempo com Giorgio Agamben, Walter Kohan e Manoel de Barros, que nos apontam uma dimensão da infância fora de uma temporalidade cronológica. Esses autores nos convidam a deslocar o olhar para deixar-nos ser encontrados e habitados pela infância.

\footnotetext{
${ }^{2}$ Grupo de Pesquisa Práticas Educativas e Formação de Professores (GPPF), da Universidade Federal do Estado do Rio de Janeiro (UNIRIO), coordenado pelas professoras Carmen Sanches Sampaio e Maria Luiza Süssekind.
} 
A partir dessas contribuições, busco tecer aproximações entre formação docente e infância, também abordando conceitos do campo da formação de professores que nos dão pistas para pensar formação docente de um outro lugar. Donald Schön, Antonio Nóvoa, Adriana Dickel, Peréz Goméz questionam modos compreendidos e hegemônicos de formar-se docente e reconhecem a prática pedagógica como território de formação, legitimando saberes criados na relação entre aprender e ensinar.

Compartilho a infância de uma pesquisa, a infância das aproximações tímidas e potentes entre formação docente e infâncias. E para isso não poderia deixar de lado acontecimentos da docência e falas de crianças. Elas estão neste artigo talvez para dar a ler sentidos e sem sentidos, para brincar com a linguagem e com os significantes, para ecoar inícios de um fazer docente outro. Ou, simplesmente, para romperem com a mera ilustração ou confirmação de teorias, pois o outro nos diz coisas sobre nós mesmos que colocam em xeque nossos (des)conhecimentos, nossas ousadas certezas e explicações sobre o mundo. Não, as falas das crianças não são analisadas e categorizadas. Suas falas é que movem a escrita do presente texto. Elas não são exemplos, são atravessamentos.

Escrevo buscando anunciar possibilidades que nos arranquem do lugar tradicional e hegemônico de fazer pesquisa e sermos professores de crianças. Pode ser que a pesquisa e este artigo nada mais sejam que colocar-nos ética e politicamente em perguntas e "problemas" que nos afetam, acolhendo palavras outras para conversar e potencializar novos questionamentos ou, simplesmente, manter vivas as perguntas que mobilizam o pensamento. $O$ que pode ser considerado um fazer (ou fazer-se) docente infantil? Como se constituir um docente que, na relação com as infâncias das crianças, se abre para uma relação infantil com o seu fazer? Uma criança me deu uma pista:

- Por eu ser criança, sei muito sobre infância! (Ana, 5 anos).

E é com essa pista que encerro esta introdução, no desejo de que ela continue ressonando nas linhas a seguir, nas palavras escolhidas para escrever, 
nos sentidos não dados sobre a infância, nas conversas que compartilho para pensar nossa tarefa docente...

\section{tecendo conversas sobre infância}

A tarefa parece ser a de ir ao encontro da infância do mundo e restaurá-la. Buscar propiciar relações "infantis" com os outros e

Etimologicamente a palavra infância ${ }^{3}$ vem do latim "infans", que significa "aquele que não fala" (o termo fan significa falante; o prefixo in marca a sua negação). Nos diferentes usos de infans, podemos destacar alguns pontos. Segundo Kohan (2011), Quintiliano (I, 1, 18) fixou uma idade compreendida até aos sete anos, na qual a criança foi considerada incapaz de falar; A propósito, infans também se referiu a pessoas de até aproximadamente quinze anos - o que nos leva a perceber que a palavra não necessariamente esteve sempre relacionada à criança pequena -, uma vez que a sua minoridade não lhes habilitava a prestar testemunho em tribunais. Assim, o autor nos diz que infans passa também a designar "muitas outras classes de marginais que não participavam da atividade pública" (KOHAN, 2011, p. 32). Essas vozes, incluindo a das crianças, não tinham validade, veracidade, potência, elas não poderiam se afirmar por elas mesmas.

Mais do que uma ausência ou negação de fala fisiológica, é possível perceber que se trata mais especificamente da condição dessa linguagem infans, de uma linguagem não tratada discursiva e politicamente, de uma fala que não se expressa ou se pronuncia de modo lógico, linguístico e articulado. Portanto, uma fala que não corresponde à condição falante, coerente e adulta.

No livro Infância e História: Destruição da experiência e origem da história, Agamben (2005) questiona a relação entre voz humana e linguagem, bem como afirma que a reflexão ocidental sobre a linguagem considerava a voz como origem

\footnotetext{
${ }^{3}$ Disponível em: <http://etimologias.dechile.net/?infancia>. Acesso em: 20 set. 2017.
} 
da dialética. Então, o autor se dedica a pensar filosoficamente acerca da infância, uma vez que a etimologia desse termo define a ausência da voz.

Contudo, Agamben explica logo nas primeiras páginas desse livro que o conceito de infância ao qual se debruçará nada tem a ver com ausência, falta ou negação de voz e linguagem. De acordo com o filósofo, a infância:

não é simplesmente um fato do qual seria possível isolar um lugar cronológico, nem algo como uma idade ou um estado psicossomático que uma psicologia ou uma paleoantropologia poderiam jamais construir como um fato humano independente da linguagem (AGAMBEN, 2005, p. 10).

Agamben demarca, então, um conceito de infância que atravessa o limite cronológico e psicológico que habitou (e habita) modos compreendidos em diferentes períodos da história ocidental - vide, por exemplo, a organização das turmas de Educação Infantil em faixas etárias; o desenvolvimento infantil dividido em etapas lineares; o "fim" da infância a partir de um determinado período de vida.

Para o autor, infância está intrinsecamente relacionada à linguagem, a uma experiência com a linguagem. Para falar da ideia da linguagem, o filósofo caminha pela teologia e pelo pressuposto da revelação divina. A tradição teológica compreende a revelação enquanto algo inalcançável pela razão humana, esta por si mesma não pode e não consegue conhecer Deus. Assim sendo, o autor diz que “o conteúdo da revelação não é uma verdade exprimível sob a forma de proposições linguísticas sobre o existente" (AGAMBEN, 2015, p. 24), uma vez que a linguística é exercício da razão e "por mais que remonte ao passado, não chega nunca a um início cronológico da linguagem, a um 'antes' da linguagem" (AGAMBEN, 2005, p. 60, grifo do autor).

A revelação divina e o desvelamento de Deus são transmitidos pelos homens através da linguagem, contudo esta revelação não revela a própria linguagem. É pela linguagem que há a possibilidade de dizer e nomear a existência de Deus (e de outros seres supremos), mas a linguagem não aparece, não se vê. “O homem vê o mundo através da linguagem, mas não vê a linguagem” (AGAMBEN, 2015, p. 24). Sendo assim: 
o que aqui é revelado não é um objeto, sobre o qual haveria muito a conhecer, mas que não é possível conhecer por falta de instrumentos de conhecimento adequados: revelado é o próprio desvelamento, o fato de que há abertura de um mundo e conhecimento (AGAMBEN, 2015, p. 24).

Contudo, essa abertura não se encontra na esfera do discurso linguístico, do significante e sentidos preexistentes. A abertura de um mundo se dá "no puro acontecimento de linguagem além ou aquém de todo significado particular" (AGAMBEN, 2015, p. 26), um acontecimento que irrompe a possibilidade de pensamento para além do discurso significante. Nas palavras de Agamben, a revelação não está na palavra significante, "mas na palavra que, sem significar nada, significa a própria significação" (AGAMBEN, 2015, p. 26). É esta significação a abertura de um mundo, um mundo outro. Essa significação pela linguagem é experiência da infância. Essa abertura de um mundo outro é infância.

Assim, algumas questões, rumo à infância, me surgem: Se a abertura de um mundo está relacionada a um acontecimento de linguagem, é possível potencializar essa abertura? O que irrompe essa abertura é somente a ausência de proposições significantes? A criação de significantes neste mundo que se abre pelo acontecer da linguagem nos coloca novamente numa esfera significante? Essas interrogações encontram sentidos a partir daquilo que o autor aborda sobre a linguagem: “O que une os homens entre si não é nem uma natureza, nem uma voz divina, nem a comum situação de prisioneiros na linguagem significante, mas a visão da própria linguagem e, por conseguinte, a experiência de seus limites, de seu 'fim'”' (AGAMBEN, 2015, p. 32).

Acredito que as reflexões de Agamben nos ajudam a pensar e, talvez, experienciar os limites da linguagem e a abertura deste mundo com as crianças...

Estava com a turma e as famílias das crianças em um passeio no Museu Nacional, na Quinta da Boa Vista. Enquanto caminhávamos pelos corredores e espaços do Museu, algumas crianças se dedicavam a olhar com atenção e sensibilidade alguns objetos, artefatos históricos e comentavam entre si e comigo a respeito de suas observações e questionamentos. Chegamos a uma sala cuja a temática era o corpo humano. Duas crianças me chamaram para ver com elas os 
esqueletos e outras peças em exposição. Uma delas, após observar por um tempo um esqueleto, compartilha que:

- A pele é a roupa do osso (Maria ${ }^{4}, 5$ anos) 5 .

A linguagem que diz, a linguagem que acontece, a linguagem da infância, a infância da linguagem. A linguagem que rompe com o discurso significante rasga sentidos dados sobre o corpo, sobre a pele e, inclusive, sobre as crianças e sobre nós. As falas das crianças me são muito caras, merecem atenção, deleite, silêncio, ressonâncias. A linguagem infantil é a linguagem da impossibilidade da norma, da normatização. A fala de Maria me faz lembrar um trecho de uma música de Dominguinhos, na qual ele diz: "Chega um tempo na vida em que a gente presta atenção, vê que nem tudo no mundo carece de explicação". Arrisco dizer que esse tempo, não precisa ser o cronológico, mas uma temporalidade em que a infância rompe com as explicações.

Agamben afirma também que o conceito de infância está nos limites da linguagem, limites que ultrapassam o seu caráter trivial e inefável. “O conceito de infância é acessível somente a um pensamento que tenha efetuado aquela 'puríssima eliminação do indizível na linguagem'” (AGAMBEN, 2005, p. 11, grifo do autor), acrescento a puríssima eliminação da explicação, tão cara nos contextos educacionais. Na tessitura entre infância e linguagem, nas ideias do filósofo, podemos dizer que a infância é o puro acontecimento de linguagem. Aponta, ainda, nessa relação entre infância e linguagem, que elas se remetem uma à outra, "a infância é a origem da linguagem e a linguagem a origem da infância" (AGAMBEN, 2005, p. 59).

[...] A experiência, a infância que aqui está em questão, não pode ser simplesmente algo que precede cronologicamente a linguagem e que, a uma certa altura, cessa de existir para versar-se na palavra, não é um paraíso que, em um determinado momento, abandonamos para sempre a fim de falar, mas coexiste originalmente com a linguagem, constitui-se aliás ela mesma na

\footnotetext{
${ }^{4}$ Para este trabalho opto por utilizar nomes fictícios, tendo em vista o processo inicial da pesquisa e o andamento das autorizações necessárias para identificação das crianças, inclusive a autorização por elas mesmas.

${ }^{5}$ Narrativas registradas por mim, enquanto professora na Educação Infantil, em uma instituição federal de ensino situada no estado do Rio de Janeiro.
} 
expropriação que a linguagem dela efetua, produzindo a cada vez o homem como sujeito (AGAMBEN, 2005, p. 59).

Agamben anuncia infância fora da dimensão cronológica e linear e a afirma como algo que não é possível de ser abandonado. O que etimologicamente nos remete à infância como a ausência de voz, de linguagem articulada e lógica, é abordado pelo filósofo como tessitura mútua entre linguagem e infância, que coexiste em outros tempos e possibilidades, gerando incômodos e nos tirando do lugar habitual de se relacionar com a infância. Em uma condição infantil com a linguagem somos impedidos de seguir pensando o que se pensava antes.

\section{infância e tempo}

[...] a tarefa de estar entre crianças consiste em fazer durar a infância todo o tempo que for possível

(Carlos Skliar, 2014).

Origem, começo, princípio, início... Algumas palavras que, por sua vez, podem remeter à concepção literal de infância; no entanto, podem ser compreendidas de modo mais intenso: como um novo que chega, habita, emerge e dá abertura à vida, à experiência, à diferença, ao acontecimento. A infância traz consigo um caminho que se abre, mas que não é possível prever; traz consigo o novo, que tira o lugar onde estávamos sentados (BARROS, 2015); traz consigo a dúvida, que um dia foi certeza.

Por isso a história não pode ser o progresso contínuo da humanidade falante ao longo do tempo linear, mas é, na sua essência, intervalo, descontinuidade, "epochée". Aquilo que tem na infância a sua pátria originária, rumo à infância e através da infância deve manter-se em viagem (AGAMBEN, 2005, p. 65, grifo do autor).

Manter-se em viagem, em uma viagem para "chegar à infância" (LEAL, 2011), uma viagem rumo à nossa "pátria original" (AGAMBEN, 2005). A ideia de viagem nos ajuda a pensar em outra temporalidade, em outros territórios, em outros caminhos, uma vez que saímos do lugar habitual de pensamento para um

\footnotetext{
${ }^{6} \mathrm{Na}$ filosofia cética, "suspensão do juízo", atitude que evita afirmar ou negar, aceitar ou refutar as coisas, como forma de atingir a imperturbabilidade (Glossário do tradutor do livro "Infầncia e história: Destruição da experiência e origem da história", Giorgio Agamben - 2005).
} 
lugar que provoca pensar, que causa desassossego e incômodo. Manter-se em viagem para e com o inesperado, impensado e imprevisto.

Uma dimensão que me convida a estar infantilmente como professora é o brincar com as crianças, estar com elas na brincadeira ou, por vezes, apreciar seus brincares. "Brincando, o homem desprende-se do tempo sagrado e o 'esquece' no tempo humano" (AGAMBEN, 2005, p. 85, grifo do autor). Essa infância se dá em outros tempos, no tempo humano, no tempo do corpo, no tempo da vida... Tempo da intensidade.

Afastando-me da concepção de infância em um tempo único, o cronológico e unidimensional, que marca e legitima diferentes ações, perspectivas, ideias, o mercado, o desenvolvimento humano, a escola, sob a égide da linearidade, do avanço e do progresso, busco experienciar o desafio de habitar outros tempos e de ser afetada por eles, apesar de ser professora numa instituição escolar ainda muito demarcada pelo tempo crónos.

Segundo Agamben, tudo que é jogo pertenceu um dia à esfera do sagrado, mas os jogos não se limitam a isso. Continuamos a inventar jogos... Um destaque especial merecem as crianças, que são capazes de criar e produzir brinquedos, brincadeiras e jogos com “qualquer velharia que lhes cai nas mãos [...]. Tudo que é velho, independentemente de sua origem sacra, é suscetível de virar brinquedo" (2005, p. 85). As crianças inventam outra temporalidade, criam possibilidades outras com as coisas e palavras já dadas. Podemos dizer que as palavras, a linguagem, já encharcadas de sentidos, de possível "origem sacra", nas mãos, olhares, vozes e bocas das crianças se tornam outras, habitam outra dimensão de experiência, se tornam brinquedos: Enquanto caminhávamos livremente no pátio para chegar ao refeitório, uma criança observou o céu e chamou algumas crianças para ver com ele: a lua e o sol estavam ao mesmo tempo no céu daquela manhã. Eu também fui convidada a olhar o céu e contemplá-lo. E perguntei às crianças: Por que será que isso acontece? Timidamente Gabriel me responde:

- A lua acorda o sol (Gabriel, 4 anos). 
Que imagem poética e viajante! Como Kohan (2014) diz, as crianças experimentam a dimensão filosófica do pensamento. A infância acorda as palavras. A profanação das palavras, dos seus significantes e do tempo. Lua e sol, professora e crianças. Nossas infâncias se encontram ao olhar o céu, ao olharmos juntos, a pensarmos juntos.

As crianças brincam com as palavras, testam a linguagem, as usam de diferentes maneiras, e com as crianças aprendemos a saborear as palavras "quando elas perturbam o sentido normal das ideias" (BARROS, 2015, p. 141). Não desejo explicar o acontecimento, mas compartilhar sentidos, tornar visível a potência do mínimo, a urgência da exposição e da sensibilidade, a possibilidade de dar a ler experiência da infância. Que a nossa tarefa docente seja fazer durar a infância nas crianças e em nós mesmos. Que vejamos e sintamos a lua acordando o sol...

\section{formação docente: modos outros de fazer-se professor(a)}

Porque um desconhecido traz uma voz nova, uma irrupção que pode mudar o pulso da terra, um gesto nos faz rever o já conhecido, a palavra antes ignorada (Carlos Skliar, 2014).

Agamben (2005), ao tratar do conceito de história, aborda uma discussão sobre tempo que muito me interessa para pensar formação docente e infância. Toda história, bem como toda cultura, é, primeiramente, uma certa experiência do tempo. Assim, uma nova cultura ou uma nova maneira de compreender e fazer história "não é possível sem uma transformação desta experiência" (AGAMBEN, 2005, p. 109). Penso que no movimento de tecer relações entre formação docente e infância, requer tratar de outras possibilidades de experiência do tempo, inclusive pensar como tais conceitos se transformam ao longo dos tempos.

O autor aborda a circularidade do tempo em Platão, sua divisão em instantes por Aristóteles, o tempo segundo o Cristianismo, as ideias de desenvolvimento e progresso como orientação do tempo linear nas sociedades ocidentais modernas, o tempo histórico em Marx... Inicialmente pontuando 
concepções dominantes e ocidentais acerca do tempo e da história, chegando "nas dobras e nas sombras da tradição cultural do ocidente" (AGAMBEN, 2005, 109) que deixam pistas e rastros de concepções diferentes sobre o tempo.

Em se tratando de formação docente, formação de professores, o modo clássico e ocidental de pensá-la e fazê-la segue também uma lógica linear, em etapas e evolução. Tradicionalmente, formação se dá na academia, numa instituição, nos cursos, para certificação e atualização dos conhecimentos. Em geral, nossas trajetórias de formação se delinearam nessa perspectiva, nessa temporalidade. Aliás, a formação escolar, a escolarização, segue esse mesmo padrão.

Nesse contexto, faz-se importante tratar aqui acerca do campo teórico e epistemológico da formação de professores. A minha escolha por pesquisar a própria prática não é uma opção solitária, mas carregada de sentidos e defesas neste campo por uma concepção de formação que possibilite nos afirmarmos como sujeitos de conhecimento, capazes de interrogar e interrogar-nos, deslocar e deslocar-nos, ser pesquisadora/pesquisador do seu fazer docente.

Tornou-se hegemônica a concepção do docente enquanto profissional que executa tarefas, práticas e políticas elaboradas por instâncias superiores que, em geral, ocupam espaços fora da escola, minimizando, portanto, saberes e fazeres produzidos no cotidiano por esses sujeitos (NÓVOA, 1995; SCHÖN, 1995). Além disso, o ato de pesquisar, nesta concepção, se articula essencial e unicamente à academia, lugar legitimado para construção de conhecimentos científicos.

O discurso "a teoria é uma coisa e a prática é outra" revela o distanciamento produzido pela "racionalidade técnica e instrumental" (PÉREZ GÓMEZ, 1995), que investe na crença de que a escola é espaço no qual as teorias são capazes de atendê-la em relação direta. Podemos ainda acrescentar o processo inicial de formação docente, no qual ainda temos currículos organizados primeiramente pelos estudos de "Fundamentos" para, posteriormente, no final do curso, estudantes estarem em aptidão para cumprir carga horária prática nos estágios supervisionados. E, ao se formarem e ingressarem nas escolas, frente aos desafios, 
logo se reforça o discurso de separação entre teoria e prática, que, por sinal, é o modo como o currículo está organizado.

Pérez Gómez (1995, p. 108) critica tal modo de pensar a docência como algo técnico, afirmando também que esta racionalidade causa frustração em professores principiantes ao enfrentarem problemas educativos "com uma bagagem de conhecimentos, estratégias e técnicas que lhes parecem inúteis nos primeiros dias de sua atividade profissional". Juntamente a outros autores, ele defende a "reflexão-na-ação". O profissional docente atua refletindo sobre seu fazer, inclusive como investigador na sala de aula. Este modo de compreender a ação docente potencializa pensar que professores produzem questões sobre a prática, refletem a respeito dela e provocam mudanças significativas no cotidiano. Portanto, "o profissional competente atua refletindo na ação, criando uma nova realidade, experimentando, corrigindo e inventando através do diálogo que estabelece com essa mesma realidade" (GÓMEZ, 1995, p. 110).

Essa concepção de formação e prática docente provoca repensar o lugar dos professores enquanto sujeitos pensantes e reflexivos. Deixam de ser concebidos como meros reprodutores de práticas pensadas por outros e potentes para questionar e participar do cotidiano escolar. No entanto, o termo reflexão gera alguns questionamentos acerca da possibilidade de professores serem meramente profissionais sem refletir sua ação docente. Garcia e Alves (2002, p. 99) nos provocam a pensar: "É possível um ser humano que não reflete enquanto pratica?"

Se, enquanto humanos, somos sujeitos de conhecimento, que lugares ocupam os conhecimentos produzidos pela e na prática? Nós, professores, que conhecimentos produzimos com as crianças? Que espaços eles ocupam a fim de ampliar e dar visibilidade ao que acontece no cotidiano? Pesquisar a própria prática é possível? Aliás, docente da escola básica pode produzir pesquisa? O que é pesquisar? Que sentidos emergem quando se abre a possibilidade de pensar em professora-pesquisadora? Estas perguntas mobilizam pensar o lugar da pesquisa e 
da docência, mobilizam reconhecer que criar e produzir conhecimentos não é privilégio da academia.

Dickel (1998) nos diz que a pesquisa docente é a possibilidade de inventar outros mundos com as crianças. Ser docente exige assumir uma postura investigativa, interrogar práticas e concepções que atravessam o cotidiano e o próprio fazer. Acredito que é necessário estar sensível às pistas e indícios que emergem na diferença, na escuta, nas tensões, nas incertezas e descobrir "que todos os caminhos levam à ignorância" (BARROS, 2015, p. 89).

Assim como a palavra infância, ignorância também tem o prefixo latim "in" que indica negação. No caso da palavra ignorância, seu significado linguístico e semântico sugere "não conhecer, não saber, não dominar o assunto". No mesmo movimento, mergulho na palavra ignorância para pensá-la não como ausência, mas com sentidos que precisam ser alimentados e potencializados.

Manoel de Barros nos convida a pensar a ignorância como final, onde todos os caminhos nos levam. Contudo, se todos os caminhos levam à ignorância, então ela não é final, mas começos, no plural, porque, se todos os caminhos se tocam e se encontram aí, então múltiplas possibilidades se abrem. Ignorância passa a ser não o fato de não saber, mas justamente a possibilidade de seguir descobrindo, inventando, perguntando e ignorando. Arrisco defender que a ignorância nos move, não o conhecimento.

Jacques Rancière, inspirado na pedagogia da igualdade do mestre ignorante Jacotot, diz: “quem busca sempre encontra. Não encontra necessariamente aquilo que buscava, menos ainda aquilo que 'é preciso encontrar'. Mas encontra alguma coisa nova, a relacionar à 'coisa' que já conhece" (RANCIÈRE, 2011, p. 57, grifos do autor). A ignorância que nos aponta a possibilidade de conhecer. Por sermos incompletos, o conhecimento obriga o reconhecimento do seu próprio limite, impelindo-nos à assunção de que o próprio conhecimento é situado e móvel.

Leal nos provoca: "Aprender com a infância. Resgatar, na infância, o que ela tem a nos ensinar. Tornar parte do aprendizado adulto a experiência da infância" 
(RANCIÈRE, 2011, p. 20). Um tempo outro que se instaura na descoberta do novo, a irrupção poética de ser, estar e compreender o mundo de um modo infantil:

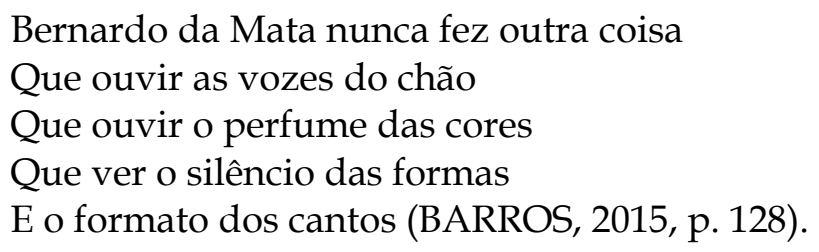

A infância é provocadora de sentidos que explodem com significados estabelecidos, resiste e inventa. Para isso, é necessário cultivar a sensibilidade do olhar, da escuta, da pele, dos gestos. Cultivar vozes, perfumes, cores, silêncios, cantos e formas... Manoel de Barros e Bernardo da Mata que o digam! E é atravessada por este modo infantil que me desafio a pesquisar e pesquisar-me, a perguntar e perguntar-me sobre o cotidiano com as crianças, bem como tornar visíveis possíveis encantamentos e potencialidades do encontro com elas.

A criança como um outro que aí está, nos olhando e nos perguntando por nós mesmos, o outro aí está nos colocando interrogações acerca de nossos modos de estar no mundo. O outro aí está ameaçando a mesmidade, tão desejada, defendida e reforçada em diferentes projetos e reformas de educação, governo e sociedade. O outro está aí nos causando desassossego, incômodo e desafiando nossas verdades refutáveis com sua presença. O outro criança, o outro infância... “Talvez tenha chegado o momento de aprendermos com as crianças o que a infância tem a nos dizer" (LEAL, 2004, p. 22).

\section{por uma formação docente infantil}

As coisas que não levam a nada têm grande importância Cada coisa ordinária é um elemento de estima As coisas sem importância são bens de poesia (Manoel de Barros, 2015).

A infância como força que acompanha a vida interrompe a linearidade do tempo, provoca-nos a perceber que a vida é território potente e fértil para ser infância. E acolhendo o desejo de Manoel de Barros, "eu queria avançar para o começo. Chegar ao criançamento das palavras" (BARROS, 2015). Experienciar pela 
infância a possibilidade de invenção e reinvenção do mundo, invenção e reinvenção de formar-se docente: ser capaz de perceber o silêncio das coisas anônimas, ter profundidades sobre o nada, ouvir as vozes do chão, ver e ouvir inexistências e desimportâncias. Uma língua outra...

A língua que estamos habituados e fomos ensinados a praticar tem normativas, regras, significantes, lógica, gramática, uma "língua de ninguém", uma "língua sem ninguém dentro" (LARROSA, 2014). A infância não habita essa língua, a infância rasga essa língua, a infância exige outra língua. Inspirando-me em Agamben e Larrosa, poderia dizer que essa língua outra reside no hiato e na passagem entre o semiótico e o semântico, entre o significante e o significado. Nesse hiato, nessa travessia, somos encontrados pela infância e, por que não, por uma língua com alguém dentro?

Em um dia agitado na escola, eu estava sozinha com a turma, e próximo ao horário da saída, as crianças ainda não tinham terminado de almoçar e algumas já estavam escovando os dentes. Ainda precisávamos guardar as agendas e eu precisava responder alguns bilhetes enviados pelos responsáveis. E a sala um pouco desarrumada... (Um parêntese importante: os responsáveis pelas crianças levam as crianças na porta da sala e também as buscam diretamente na sala da turma). Recordo de estar na porta da sala observando um grupo que estava do lado de dentro e outro grupo que, ao sair do banheiro, após escovarem os dentes, decidiram brincar no pátio. E eu tentando manter a “ordem”. Para quê?

De modo singelo, Ana, que estava observando as pequenas plantas e flores do canteiro do pátio, me chama e diz:

- Camila, você precisa cheirar essas flores. Elas têm cheiro de hortelã! (Ana, 5 anos).

Num primeiro momento, eu quase recusei este convite e Ana, percebendo o meu corpo pronto a não sair da porta para "tomar conta" dos dois grupos, pega na minha mão e me leva até as flores. É esse o tempo a que esta pesquisa e minha prática docente se arriscam, se desafiam e buscam. Um tempo ao qual quem dá o tom é a infância, o que nos é comum, a nossa pátria original (AGAMBEN, 2005). 
E é necessário e urgente defender que pesquisa em educação e formação docente também acontecem no encontro das mãos, no cheirar de uma flor, na partilha de sensações, na dúvida, nos gestos, nas narrativas, nas conversas. Talvez, pesquisar e escrever em outra língua, "uma língua que nos permita viver no mundo, fazer a experiência do mundo, e elaborar com outros o sentido (ou a ausência de sentido) do que nos acontece" (LARROSA, 2014, p. 65). Esse artigo pretendeu habitar, de algum modo, outra língua, a encontrar-se com a presença enigmática e poética da infância que nos coloca cara a cara com algo desconhecido, estranho e tremulante, suspendendo a certeza audaciosa que temos sobre nós e sobre tudo.

A compreensão de infância que acolho neste artigo se aproxima e potencializa o que defendo como formação docente, enquanto experiência que nos atravessa, desestabiliza e oferece outros modos de sermos professoras e professores. Uma formação outra que rasga o que nos habita apontando desvios e caminhos que nos tiram do lugar e forçam o pensamento a pensar nosso próprio fazer docente com as crianças.

Portanto, acredito que formação docente também se dá pelos atravessamentos e acontecimentos da docência, nas redes tecidas com outros docentes e com as crianças, nas tensões e conflitos gerados pelas incertezas e pelo novo. E, inclusive, pelos silêncios, gestos, rostos, toques, narrativas e olhares que podem constituir e dar vida ao fazer docente. Quiçá uma formação que se faça pelos encantamentos, uma formação que se sente e se inventa com o outro, com as infâncias. Quiçá buscar uma relação infantil com a docência, habitar outra temporalidade para que exista um encontro com as infâncias. Quiçá encontrar (-se) com enigmas da infância na Educação Infantil. Assim como uma criança certa vez me disse:

- Para você ter infância, é só você ficar baixinha (Luiza, 5 anos).

É necessário ser menor, estar e se colocar em condição de minoridade, tornar-se pequeno. Luíza faz ressoar que não precisamos "voltar para a infância", resgatá-la - não se volta no tempo cronológico, a infância não está somente no dito 
passado -, infância é também hoje, presente, e estar e se encontrar com a infância nos exige outra relação com o corpo, com o tempo, com as coisas menores. Por uma formação docente que acolha e se abra aos acontecimentos. Por uma formação que se abaixe para ver, tocar e sentir outra estética de relação e de presença na escola. Por uma formação que deseje ter infância. Por uma formação que se faça baixinha e com os outros, com as crianças, com as infâncias.

\section{referências}

AGAMBEN, G. Infância e história: destruição da experiência e origem da história. Belo Horizonte: Editora UFMG, 2005.

AGAMBEN, G. A potência do pensamento: ensaios e conferências. Belo Horizonte: Editora Autêntica, 2015.

BARROS, M. de. Meu quintal é maior do que o mundo: Antologia. Rio de Janeiro: Objetiva, 2015.

DICKEL, A. Que sentido há em se falar em professor-pesquisador no contexto atual: contribuições para o debate. In: GERALDI, C. M. G; FIORENTINI, D. PEREIRA, E. M. de A. (Orgs.). Cartografias do trabalho docente: professor(a)-pesquisador(a). Campinas, SP: Mercado das Letras, 1998.

GARCIA, R. L; ALVES, N. Conversa sobre pesquisa. In: ESTEBAN, M. T; ZACCUR, E. (Orgs.). Professora pesquisadora: uma práxis em construção. Rio de Janeiro: DP\&A, 2002.

GÓMEZ, A. P. O pensamento prático do professor: a formação do professor como profissional reflexivo. In: NÓVOA, A. (Org.). Os professores e a sua formação. Lisboa: Publicações Dom Quixote, 1995.

KOHAN. W. Infância. Entre educação e filosofia. Belo Horizonte: Autêntica Editora, 2011.

KOHAN. W. Infancia, política y pensamiento: ensayos de filosofía y educación. Buenos Aires: Editorial Fundación la Hendija, 2014.

LARROSA, J. Pedagogia Profana: danças, piruetas e mascaradas. Belo Horizonte: Autêntica Editora, 2013.

LARROSA, J. Tremores: escritos sobre experiência. Belo Horizonte: Autêntica Editora, 2014.

LEAL, B. Leituras da infância na poesia de Manoel de Barros. In: KOHAN, Walter (Org.) Lugares da infância: Filosofia. Rio de Janeiro: DP\&A, 2004.

LEAL, B. Chegar à infância. Niterói: EdUFF, 2011.

NÓVOA, A. Formação de professores e profissão docente. In: NÓVOA, A. (Org.). Os professores e a sua formação. Lisboa: Publicações Dom Quixote, 1995.

RANCIÈRE, J. O mestre ignorante: cinco lições sobre a emancipação intelectual. Belo Horizonte: Autêntica Editora, 2011.

SCHÖN, D. Formar professores como profissionais reflexivos. In: NÓVOA, A. (Org.). Os professores e a sua formação. Lisboa: Publicações Dom Quixote, 1995.

SKLIAR, C. Desobedecer a linguagem: Educar. Belo Horizonte: Autêntica Editora, 2014.

recebido em: 28.12 .2017

aprovado em: 17.03 .2018 